\title{
MODIFIED SINGLE ROLL FLAP APPROACH FOR SIMULTANEOUS IMPLANT PLACEMENT AND RECESSION COVERAGE
}

\author{
Kamen Kotsilkov \\ Department of Periodontology, Faculty of Dental Medicine, Medical University \\ Sofia, Bulgaria.
}

\begin{abstract}
:
PURPOSE: This presentation demonstrates the application of the recently described modified single roll flap approach in a combined approach with the coronally advanced flap for simultaneous root coverage and implant placement with augmentation of an alveolar ridge defect.

MATERIAL/METHODS: A 45 years old patient presented with complaints of teeth hypersensitivity and gum recessions as a result of an extraction of a fractured tooth. The clinical examination revealed an edentulous area in the lower right mandible, position \#46, presenting a III class Siebert alveolar ridge defect, with a predominant horizontal volume insufficiency.Root exposures with caries lesions were observed on the neighboring teeth - \#44, \#45, \#47. Usually, such a combined soft tissue and bone defects require multiple surgeries to achieve complete tissue augmentation. In this case, a new combined approach was performed, using the recently described by the author modified single roll flap and the protocol of the lateral approach of the coronally advanced flap for the lower jaw.

RESULT: A complete root coverage, both bucally and approximaly, was present on the 4th month after surgery. In the edentulous area, a sufficient volume augmentation was observed with a presence of an adequate height and thickness of the peri-implant mucosa to achieve a good long term success of the implant born crown.

CONCLUSION: The presented case proved the benefits of the newly described modified roll flap and the possibility this approach to be implemented in different surgical techniques, thus enlarging the indications of its application.
\end{abstract}

Keywords: implant placement, root coverage, periimplant soft tissue augmentation, modified single roll flap,

\section{BACKGROUND:}

One of the most common consequences following a tooth extraction is the formation of an alveolar ridge defect due to the resorptionof the alveolar bone. In cases of a presence of bone dehiscence on the neighboring teeth, a gingival recession could result. These cases usually require a combined approach, including procedures for bone augmentation, gingival augmentation and root coverage to achieve a functional dental implant.

AIM:

This presentation demonstrates the application of the recently described modified single roll flap approach in a combined approach with the coronally advanced flap for simultaneous root coverage and implant placement with augmentation of an alveolar ridge defect.

\section{CASE DESCRIPTION:}

A 45 years old patient presented with complaints of teeth hypersensitivity and gum recessionsas a result of an extraction of a fractured tooth. The clinical examination revealed an edentulous area lower right mandible, position \#46. (Fig.1.)

Fig. 1. Initial clinical status.

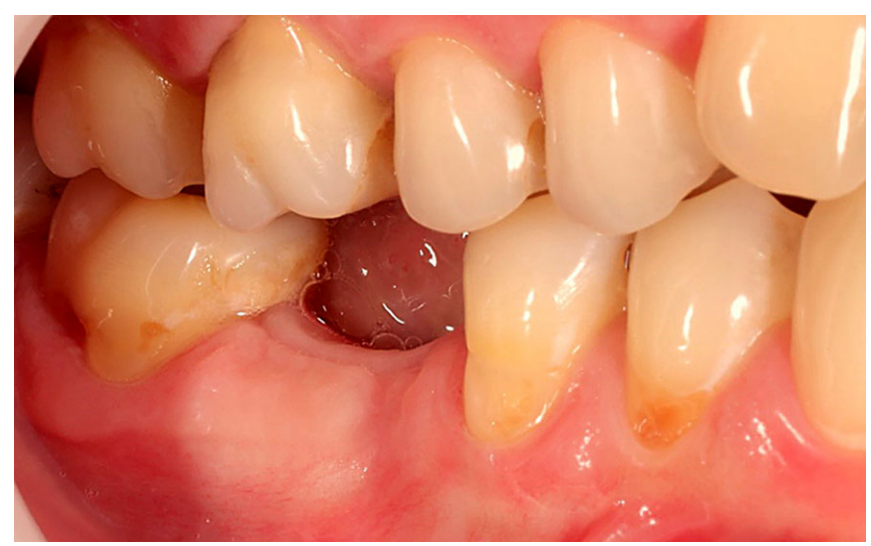


The first molar was extracted before 4 months due to vertical root fracture. Root exposures with caries lesions were observed on the neighboring teeth - \#44, \#45, \#47. (Fig.2.)

Fig. 2. Cervical caries lesions and non-definable CEJ $44,47$.
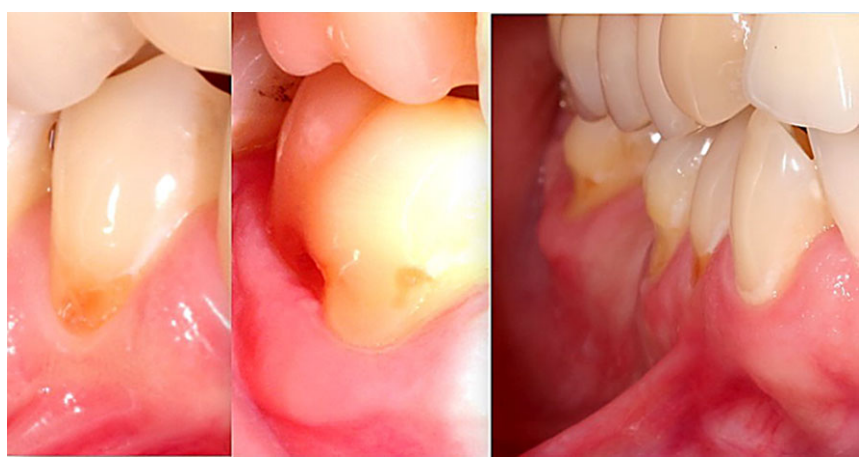

The existing gingival recessions were classified using the classification of Rotundo et al. 2011 [1]. Tooth \#47 has more than $2 \mathrm{~mm}$ keratinized gingiva, has a cervical lesion and loss of height of the mesial papilla - ABB, \#45 has less than $2 \mathrm{~mm}$ keratinized gingiva, cervical lesion and loss of distal papilla height - BBB, and \#44 - > $2 \mathrm{~mm}$ keratinized gingiva, cervical lesion, no interdental tissue loss BBA. (Fig.3.)

Fig. 3. Gingival recessions classified according to Rotundo et al. 2011.

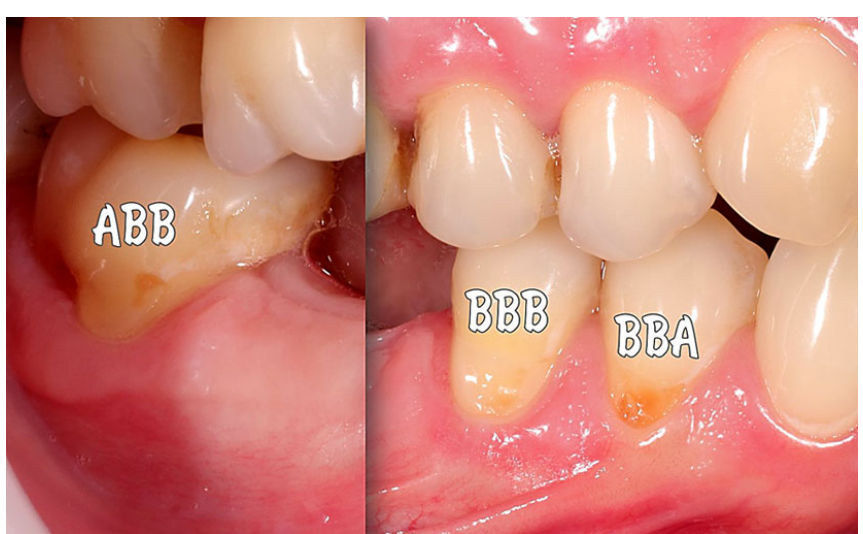

Composite restorations were made to treat the cervical caries lesions and to restore the proper emergency profile of the teeth. (Fig.4.).

Fig. 4. Cervical composite restorations.

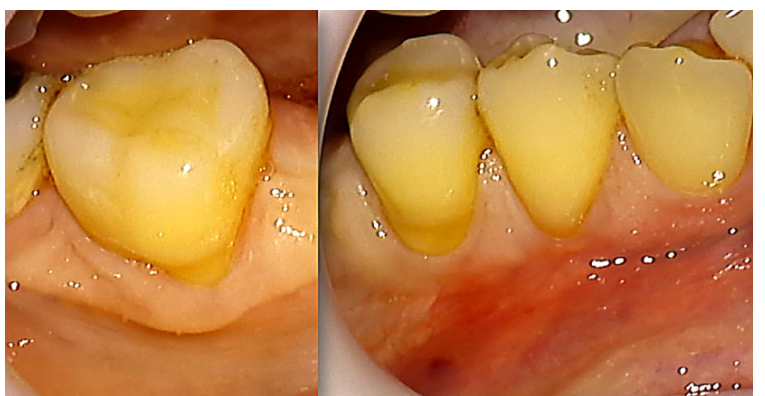

Regarding the edentulous area, a III class Siebert alveolar ridge defect was present, with a predominant horizontal volume insufficiency. The CBCT analysis showed that enough bone volume is present for successful implantation without a bone augmentation procedure.A surgical stent for the correct 3D implant positioning was prepared. (Fig.5.)

Fig. 5. CBCT analysis and surgical stent planning.

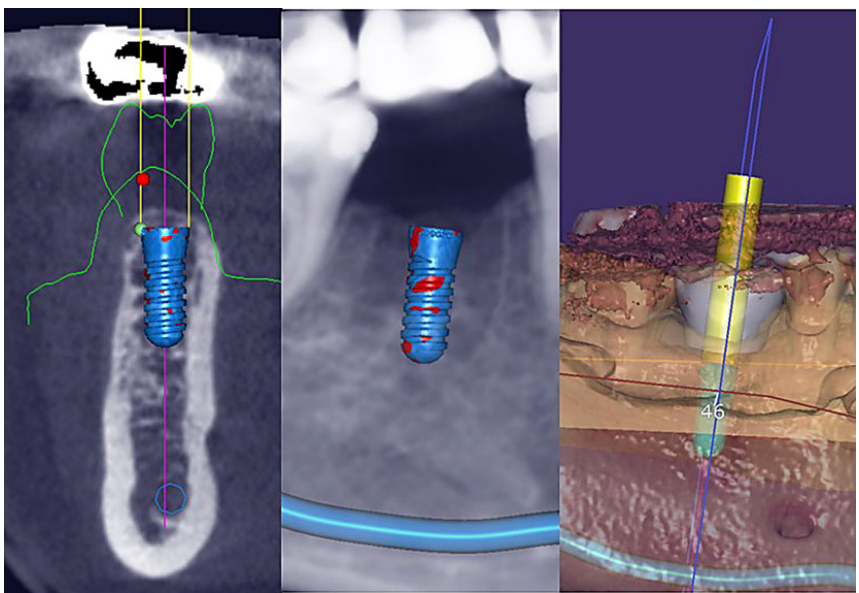

Usually, such a combined soft tissue and bone defects require multiple surgeries to achieve complete tissue augmentation. In this case, a new combined approach was performed, using the recently described by the authormodified single roll flap (Kotsilkov 2017) [2] and the protocol of the lateral approach of the coronally advanced flap for the lower jaw(de Sanctiset al. 2011) [3].

The first step is todetermine the necessity for a connective tissue graft. The selection protocol described by Stefanini et al. 2018 [4] was applied, and it was concluded that graft is needed for all teeth in the area, \#44, \#45 because the keratinized tissue height was $<1 \mathrm{~mm}$, and for $\# 47$ because the loss of papillae height. (Fig. 6.)

Fig. 6. Analysis for connective tissue graft necessity.

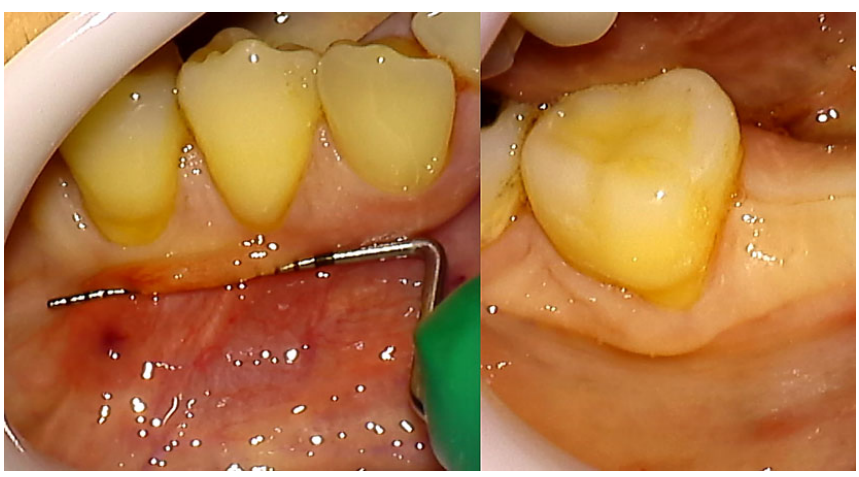

The incision design combined the two applied surgical protocols with oblique incisions at the papillae of \#44 and $\# 45$, the starting point was determined by transferring the distance of the recession depthfrom the tip of the papilla (Fig. 7.) 
Fig. 7. Determining the level of the oblique incisions.

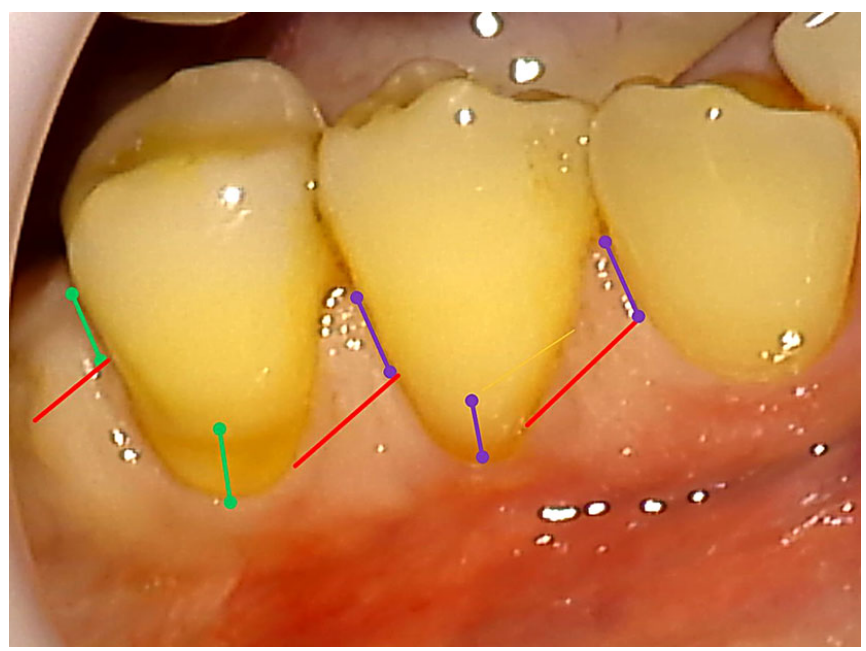

In the edentulous area, the modified roll flap incision wad used with two full thickness vertical incisions $2 \mathrm{~mm}$ from the sulcus of the adjacent teeth, connected with one para-crestal horizontal cut, thus forming a U-shaped zone. The incision was extended with sharp incisions in the buccal part of the papillae, connecting with the distal oblique incision of the \#45 (Fig.8.).

Fig. 8. Completed incisions design.

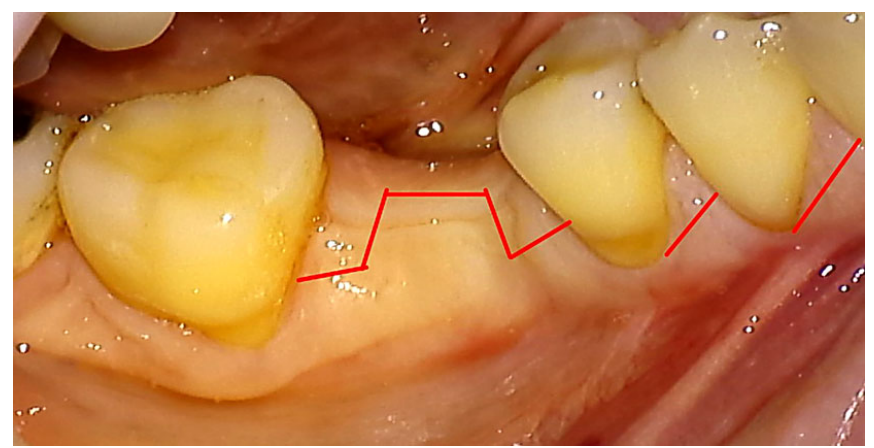

The surgery starts with the Modified roll flap [2] preparation - marking of the center of the implant site, thus giving the size of the roll flap, which after deepitelialization and provided $3 \mathrm{~mm}$ thick connective tissue to augment the buccal soft tissue of the implant. (Fig. 9.)
Fig. 9. Modified Roll flap design.

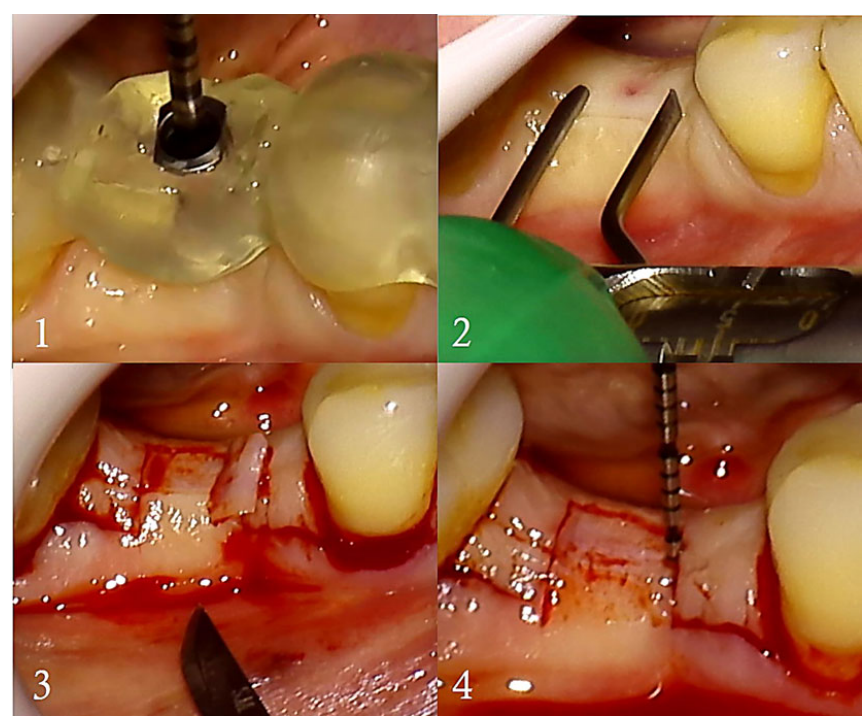

The following steps are corresponding to the splitfull-split flap design [3]. The surgical papillae are prepared split-thickness, followed by full thickness preparation buccal flap and the roll flap and finished with the deep and superficial periosteal incisions to ensure the passivation of the coronal flap advancement. (Fig. 10)

Fig. 10. Flap preparation and passivation.

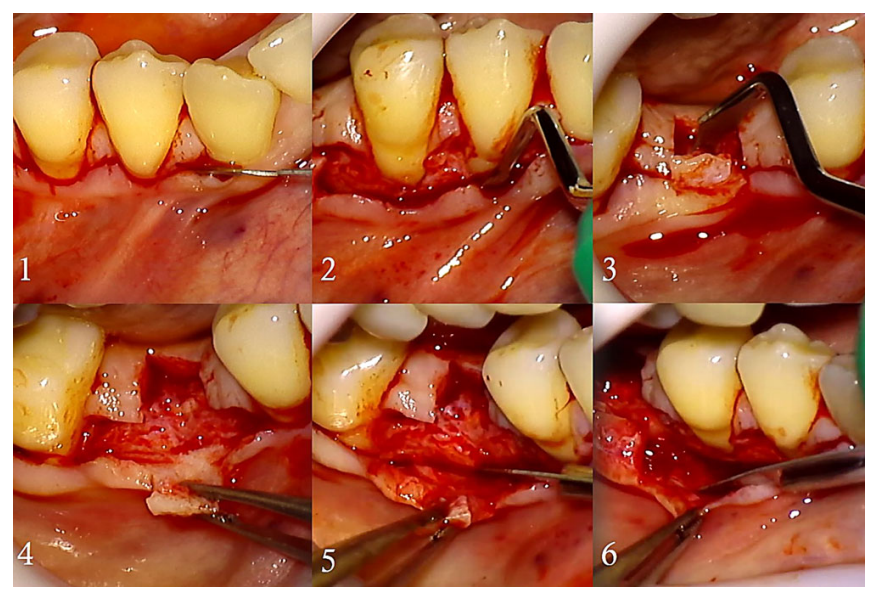

One of the most important steps is the proper deepithelialization of the anatomical papillae. In the described modification, the soft tissue sideways of the roll flap forms the peri-implant papillae and is also partially deepithelialized to the level of desired coronal flap position, thus providing a stable anchorage for the connective tissue graft fixation and for stable coronal flap advancement. (Fig. 11.) 
Fig. 11. Anatomical papillae deepithelialization.

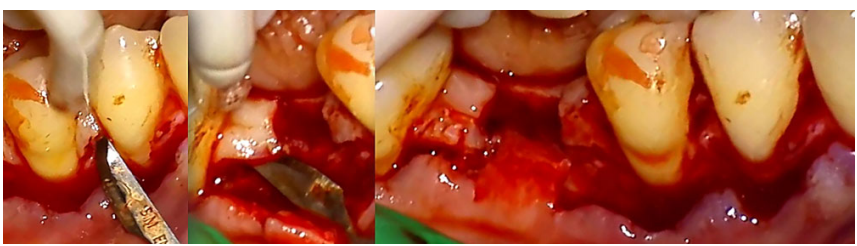

The prepared roll flap is folded and sutured to the inner surface of the buccal flap with a 7/0 PGA resorbable suture, providing $6 \mathrm{~mm}$ in height and $4 \mathrm{~mm}$ in thickness soft tissue to protect the buccal implant wall. (Fig. 12.) flap.

Fig. 12. Gingival augmentation provided by the roll

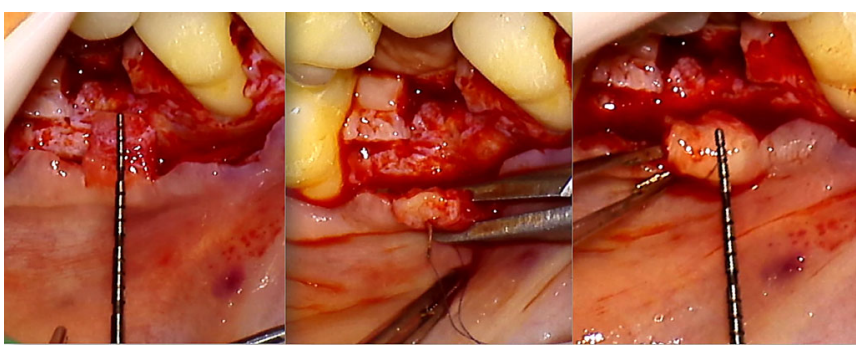

The implant site is prepared to provide $3 \mathrm{~mm}$ thickness of the peri-implant soft tissues, required to ensure crestal bone stability of the peri-implant bone. The osteotomy was done using a prefabricated surgical stent. A Straumann ${ }^{\circledR}$ Bone Level Tapered 4,1/12mm implant was placed with a d $5 \mathrm{~mm}, 4 \mathrm{~mm}$ high healing abutment. (Fig. 13.)

Fig. 13. Implant placement.

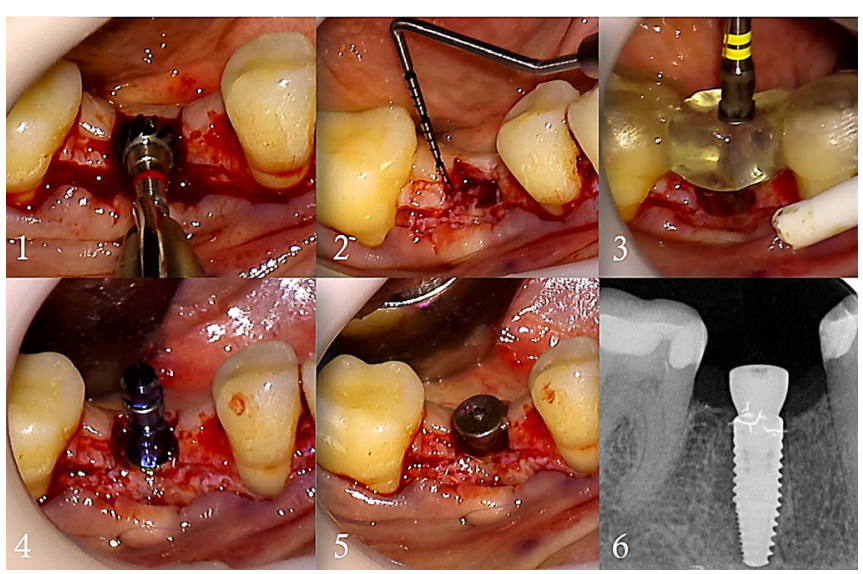

The connective tissue graft chosen for this case was a deepithelializedautogenous gingival graft from the posterior palate segment. This graft is characterized by high collagen content and provides a stable long-term tissue volume, and was sutured to the base of the deepithelialized papillae at the level of the desired final gingival margin. The dimensions were calculated to provide a $4 \mathrm{~mm}$ high graft for each tooth. The thickness was $1 \mathrm{~mm}$ for \#45, \#44, and $1,5 \mathrm{~mm}$ for $\# 46$ - where restoration of the mesial papilla is also required. This protocol ensures that enough soft tissue is present to stabilize the flap in coronal position Zucchelli et al. 2010. [5]. (Fig. 14.)

Fig. 14. Connective tissue graft preparation and placement.

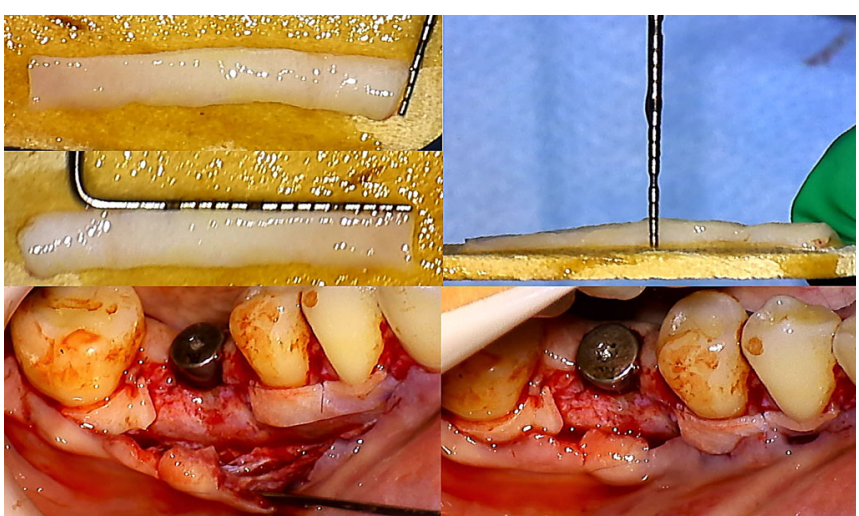

The flap was sutured in a coronal position with sling sutures using 6/0 PGA. The fixation of the flap to the periimplant papillae was ensured with O-type sutures with 5/0 ePTFE. (Fig. 15.)

Fig. 15. Coronal flap advancement and fixation.

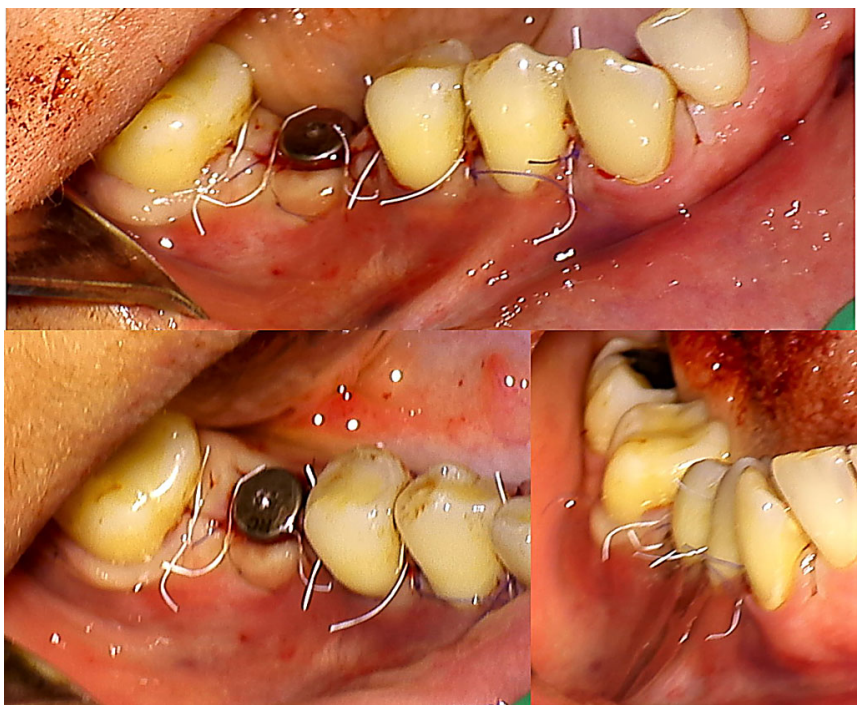

RESULT:

The preparation only of the buccal flap and minimizing the graft dimensions with the recently described minimally invasive surgical approach[2] provided a fast and uneventful primary healing with proper tissue volume and color, without any scar formation, even on the 7 th day. (Fig. 16.) 
Fig. 16. 7th-day result.

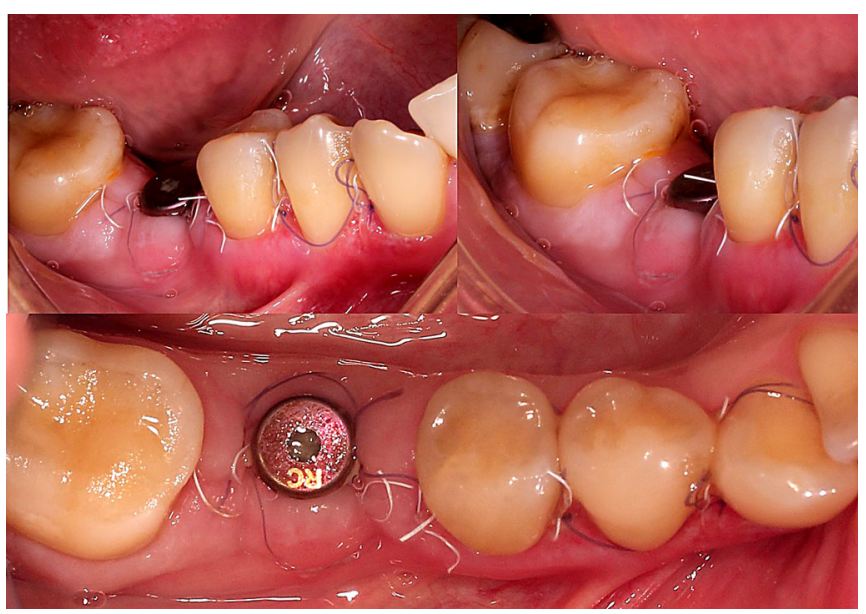

A complete root coverage, both bucall and approximal, was present on the 4th month after surgery. In the edentulous area, a sufficient volume augmentation was observed with a presence of an adequate height and thickness of the peri-implant mucosa to achieve a good long term success of the implant born crown.(Fig.17.)

Fig. 17. 4th-month result

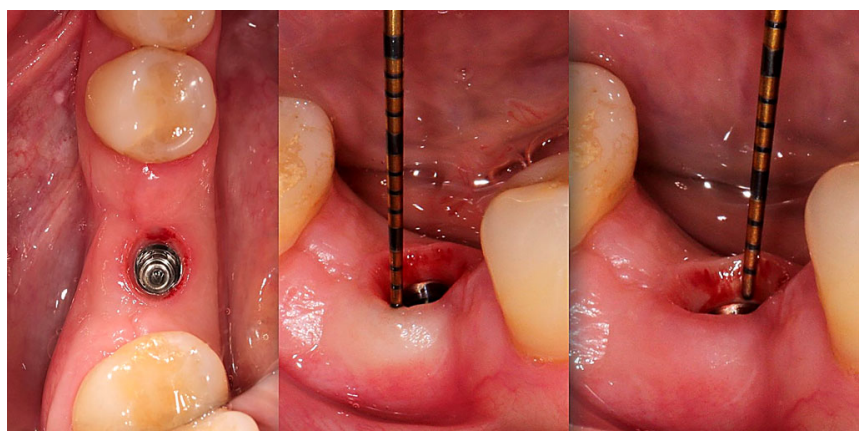

The provisional crown was fabricated with a proper critical emergency profile to provide sufficient space for the marginal soft tissue. The $\mathrm{x}$-ray showed a stable bone volume. (Fig. 18.)

Fig. 18. Provisional crown design and placement.

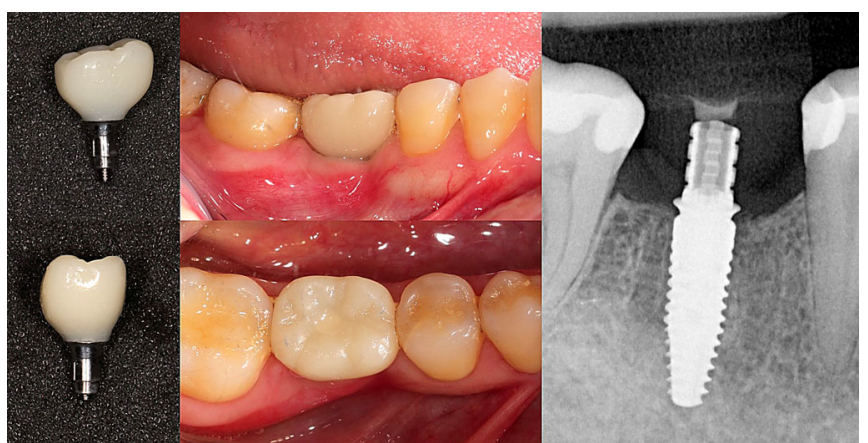

\section{DISCUSSION:}

The ability of the soft tissue grafts to promote soft tissue stability and diminish bone remodeling after implantation has been discussed in recent years. Thereis a significant amount of controlled prospective studies by Linkeviciuset al.[6-8] with medium size patient samples indicating that thin, soft tissues lead to increased marginal bone loss compared to thick, soft tissues at implants. These studies also demonstrate that adding a submarginal connective tissue graft in sites with thin peri-implant tissues diminishes the boneloss to levels not different from the thick, soft tissue sites.

A recently published case series follow up from $\mathrm{G}$. Zucchelli [9] and coworkers evaluating the transmucosal implant placement with submarginal connective tissue graft in areas of shallow buccal bone dehiscence demonstrated that the submarginal CTG technique was able to provide simultaneous vertical and horizontal soft tissue increases around single implants with shallow buccal bone dehiscence and no buccal mucosal recession or clinical signs of mucositis or peri-implantitis at $1^{\text {st }}$ and $3^{\text {rd }}$ years. A significant increase in keratinized tissue height was also found at $3^{\text {rd }}$ year. No significant marginal bone loss was recorded.

The usual approach in similar cases with gingival recessions and an alveolar ridge defect requires multiple stage surgical procedures starting with a procedure for horizontal and vertical gingival augmentation, followed by an implantation procedure after 3-4 months, and finally a recession coverage procedure with a simultaneous horizontal gingival augmentation in the zone of the implantation during the healing abutment placement procedure.

The described in this report combined approach provides a simultaneous root coverage and peri-implant soft tissue augmentation in a single surgical procedure. This reduces the morbidity of the treatment, on the one hand decreasing the number of procedures and on the other reducing the number and the dimensions of the connective tissue grafts.

Conditions are created for the restoration of the function during the prosthetic treatment $[10,11,12]$.

\section{CONCLUSION:}

The presented case proved the benefits of the newly described modified roll flap and the possibility this approach to be implemented in different surgical techniques, thus enlarging the indications of its application. 


\section{REFERENCES:}

1. Rotundo R, Mori M, Bonaccini $\mathrm{D}$, Baldi C. Intra- and inter-rater agreement of a new classification system of gingival recession defects. Eur J Oral Implantol. 2011 Summer;4(2):127-33. [PubMed]

2. Kotsilkov K. Modified single roll flap approach forsimultaneous implant placement and gingival augmentation. J of IMAB. 2017 Jul-Sep;23(3): 1667-72. [Crossref]

3. de Sanctis M, Baldini N, Goracci C, Zucchelli G. Coronally advanced flap associated with a connective tissue graft for the treatment of multiple recession defects in mandibular posterior teeth. Int $J$ Periodontics Restorative Dent. 2011 Nov-Dec;31(6):623-30. [PubMed]

4. Stefanini M, Marzadori M, Aroca S, Felice P, Sangiorgi M, Zucchelli G. Decision making in root-coverage procedures for the esthetic outcome. Periodontol 2000. 2018 Jun;77(1):5464. [PubMed]

5. Zucchelli G, Mele M, Stefanini M, Mazzotti C, Marzadori M, Montebugnoli L, et al. Patient morbid- ity and root coverage outcome after subepithelial connective tissue and deepithelialized grafts: a comparative randomized-controlled clinical trial. $J$ ClinPeriodontol. 2010 Aug 1;37(8): 728-38. [PubMed]

6. Linkevicius $\mathrm{T}$, Puisys A, Linkeviciene L, Peciuliene V, Schlee M. Crestal Bone Stability around Implants with Horizontally Matching Connection after Soft Tissue Thickening: A Prospective Clinical Trial. Clin Implant Dent Relat Res. 2015 Jun;17(3):497-508. [PubMed]

7. Puisys A, Linkevicius T. The influence of mucosal tissue thickening on crestal bone stability around bonelevel implants. A prospective controlled clinical trial. Clin Oral Implants Res. 2015 Feb;26(2):123-9. [PubMed]

8. Linkevicius T, Puisys A, Steigmann M, Vindasiute E, Linkeviciene L. Influence of Vertical Soft Tissue Thickness on Crestal Bone Changes Around Implants with Platform Switching: A Comparative Clinical Study. Clin Implant Dent Relat Res. 2015 Dec;17(6):1228-36. [PubMed]
9. Stefanini M, Felice P, Mazzotti C, Marzadori M, Gherlone EF, Zucchelli G. Transmucosal Implant Placement with Submarginal Connective Tissue Graft in Area of Shallow Buccal Bone Dehiscence: A ThreeYear Follow-Up Case Series. Int J Periodontics Restorative Dent. 2016 SepOct;36(5):621-30. [PubMed]

10. Konstantinova D, Dimova M, Naydenova D. Impact of food preferences on the development of pathological changes in the masticatory apparatus in young patients. J of IMAB. 2016 Jul-Sep;22(3):1230-1234. [Crossref]

11. Hadjieva H, Dimova M, Peev T. Clinical procedures contributing to the aesthetic result in total prosthetic treatment. Zabolekarski pregled. 2006; 88(2):108-112. [in Bulgarian]

12. Dimova M. An index of patient's satisfaction after using of provisional restorations in treatment of tooth crown's and dentition restorations- crowns and bridges. Folia Medica. 1998; 40(3A):145.

Please cite this article as: Kotsilkov K. Modified single roll flap approach for simultaneous implant placement and recession coverage. J of IMAB. 2021 Apr-Jun;27(2):3778-3783. DOI: https://doi.org/10.5272/jimab.2021272.3778

Received: 19/08/2020; Published online: 08/06/2021

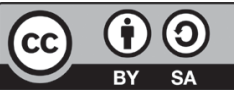

Address for correspondence:

Kamen Kotsilkov, DDS, PhD - Associate Professor,

Department of Periodontology, Faculty of Dental Medicine, Medical University - Sofia,

1, St. Georgi Sofiiski str., Sofia, Bulgaria.

Private Practice: Dental Clinic Kotsilkovi, 24,Vidinikuli str., Sofia, Bulgaria.

E-mail: kamenkotsilkov@gmail.com, 